\title{
Brazilian guidelines for the application of transcranial ultrasound as a diagnostic test for the confirmation of brain death
}

\section{Diretrizes brasileiras para o uso do ultrassom transcraniano como teste diagnóstico de confirmação de morte cerebral}

\begin{abstract}
Marcos C. Lange1, Viviane H. F. Zétola', Maramélia Miranda-Alves², Carla H. C. Moro, Carlos E. Silvado', Daniela L. G. Rodrigues 4 , Edilene Guiotti di Gregorio ${ }^{5}$, Gisele S. Silva ${ }^{6}$, Jamary Oliveira-Filho', Marco T. A. Perdatella ${ }^{8}$, Octávio M. Pontes-Neto ${ }^{9}$, Soraia R. C. Fábio ${ }^{9}$, Wagner M. Avelar ${ }^{10}$, Gabriel R. de Freitas ${ }^{11}$, Task Force Group of the Neurosonology Department of the Brazilian Academy of Neurology
\end{abstract}

\begin{abstract}
Neurosonological studies, specifically transcranial Doppler (TCD) and transcranial color-coded duplex (TCCD), have high level of specificity and sensitivity and they are used as complementary tests for the diagnosis of brain death (BD). A group of experts, from the Neurosonology Department of the Brazilian Academy of Neurology, created a task force to determine the criteria for the following aspects of diagnosing BD in Brazil: the reliability of TCD methodology; the reliability of TCCD methodology; neurosonology training and skills; the diagnosis of encephalic circulatory arrest; and exam documentation for BD. The results of this meeting are presented in the current paper.
\end{abstract}

Key words: transcranial Doppler, encephalic circulatory arrest, brain death.

\section{RESUMO}

Estudos neurossonológicos, especialmente o Doppler transcraniano (DTC) e o duplex transcraniano codificado a cores (DTCC), apresentam elevados níveis de especificidade e sensibilidade quando utilizados como exames complementares no diagnóstico de morte encefálica (ME). Um grupo de peritos do Departamento Científico de Doppler transcraniano da Academia Brasileira de Neurologia criou uma força-tarefa de forma a determinar os critérios neurossonológicos para os seguintes aspectos no diagnóstico de ME no Brasil: metodologia do DTC; metodologia do DTCC; treinamento e habilidades em Neurossonologia; diagnóstico de parada circulatória encefálica e documentação do exame para a ME. Os resultados deste encontro foram apresentados neste artigo.

Palavras-Chave: Doppler transcraniano, parada circulatória encefálica, morte encefálica.

\footnotetext{
1 Serviço de Neurologia, Hospital de Clínicas da Universidade Federal do Paraná, Curitiba PR, Brazil;

${ }^{2}$ Universidade Federal de São Paulo (UNIFESP) e Hospital São Luiz, São Paulo SP, Brazil;

${ }^{3}$ Unidade de AVC do Hospital Municipal São José e Universidade da Região de Joinville, Joinville SC, Brazil;

${ }^{4}$ Chefe do Serviço de Neurossonologia da UNIFESP, São Paulo SP, Brazil;

${ }^{5}$ Neurologista, Goiânia GO, Brazil;

${ }^{6}$ Professora Adjunto da Disciplina de Neurologia Clínica da UNIFESP e Coordenadora Médica do Programa Integrado de Neurologia Hospital Israelita Albert Einstein (HIAE), São Paulo SP, Brazil;

${ }^{7}$ Clínica de AVC da Universidade Federal da Bahia, Salvador BA, Brazil;

${ }^{8}$ Hospital Geral de Goiânia e Secretaria Estadual de Saúde, Goiânia GO, Brazil;

${ }^{9}$ Serviço de Neurologia Vascular e Neurossonologia do Departamento de Neurociências e Ciências do Comportamento do Hospital das Clínicas da Faculdade de Medicina de Ribeirão Preto da Universidade de São Paulo, Ribeirão Preto SP, Brazil;

${ }^{10}$ Laboratório de Neurossonologia do Hospital das Clínicas da Universidade Estadual de Campinas (UNICAMP), Campinas SP, Brazil;

11 Instituto D'Or de Pesquisa e Ensino (IDOR), Rio de Janeiro RJ, Brazil.

Correspondence: Marcos C. Lange; Rua Vergueiro 1.353 / sala 1404 / $14^{\circ}$ andar / Torre Norte Top Towers Office; $04101-000$ São Paulo SP - Brasil; E-mail: lange@ufpr.br

Conflict of interest: There is no conflict of interest to declare.
}

Received 09 December 2011; Received in final form 29 December 2011; Accepted 05 January 2012 
The field of Neurosonology has evolved from Neurology and Neuroscience, and it is primarily concerned with the application of ultrasound energy for diagnostic and therapeutic purposes. In clinical practice, the transcranial Doppler (TCD) ultrasound is the most recognized and widely accepted method in Neurosonology. Recently, the use of a technique known as transcranial color duplex (TCCD) has advanced transcranial ultrasound imaging capabilities.

Based on a large body of sound scientific evidence, several sets of international guidelines have recommended the TCD as a valid and robust method to confirm the clinical diagnosis of brain death $(\mathrm{BD})^{1}$. In Brazil, a diagnosis of $\mathrm{BD}$ requires at least one complementary test, including TCD, which has the following advantages: non-invasiveness, high portability, and low cost. The present article has outlined the first set of Brazilian guidelines for applying transcranial ultrasound as a diagnostic test to confirm BD.

\section{METHODS}

The guidelines in the present paper resulted from several meetings and from a considerable amount of effort from a task force group of the Neurosonology Department of the Brazilian Academy of Neurology. Seven members of such group conducted an extensive literature review on Medline and Scielo databases for articles on the use of transcranial ultrasound for BD. Then, the Committee was divided into five working groups for the following specific areas: reliability of TCD methodology; reliability of TCCD methodology; Neurosonology training and skills; diagnostic criteria for encephalic circulatory arrest (ECA); and BD exam documentation.

A draft containing the summarized evidence for each topic was critically analyzed and discussed by all members of the task force group. All the members of the Neurosonology Department of the Brazilian Academy of Neurology were invited to a final meeting regarding the recommendations, which occurred in September, 2011, during the Brazilian Congress of Cerebrovascular Diseases in Gramado, Brazil. A vote on a topic was considered to reach final consensus when there were no more than three dissenting votes.

Each recommendation was graded according to the following criteria: A that established as useful/predictive or not useful/ predictive for the given condition in the specified population; $\mathrm{B}$, probably useful/predictive or not useful/predictive for the given condition in the specified populations; $\mathrm{C}$, possibly useful/predictive or not useful/predictive for the given condition in the specified population; D, inadequate or conflicting data, given current knowledge or the test/predictor unproven ${ }^{2}$.

Regarding the confidence levels for each recommendation, the following criteria were applied:

- Class I: evidence provided by a prospective study in a broad spectrum of patients with the suspected condition, using a golden-standard to define cases, in which the test was applied in blinded evaluation and enabled assessment with accurate diagnostic tests.

- Class II: evidence provided by a prospective study in a narrow spectrum of patients with the suspected conditions or by a well-designed retrospective study of a broad spectrum of patients with a suspected condition (by golden-standard), compared with a broad spectrum of controls in which the test was applied in a blinded evaluation and enabled assessment of appropriate and accurate diagnostic tests.

- Class III: evidence provided by a retrospective study, in which the test was applied in a blinded evaluation to a narrow spectrum of patients with the established condition or controls.

- Class IV: evidence from a test that was not applied in a blinded fashion or evidence provided by expert opinion or descriptive case series ${ }^{2}$.

\section{RESULTS}

\section{Transcranial Doppler}

This is a noninvasive ultrasound technique that can assess blood flow velocity in the main intracranial arteries. Introduced in the daily clinical practice by Aaslid, in $1982^{3}$, this technique has proven to be useful for primary prevention of stroke in patients with sickle cell disease, diagnosing intracranial stenoses, evaluating and treating acute stroke patients, and diagnosing ECA in patients under protocol evaluation for $\mathrm{BD}^{1}$. Currently, TCD is the only approved noninvasive method to evaluate intracranial artery flow patterns in patients with suspected BD. TCD is less susceptible than an electroencephalogram (EEG) to falsepositive results in patients with residual effects of sedative medications $^{4-6}$.

If rigorous criteria are followed, the sensitivity and specificity of TCD for BD confirmation, when compared to cerebral angiography as the golden-standard, are 88 and $100 \%$, respectively (Level A, Class 2$)^{1,7}$. However, false-negative cases may occur in patients with poor transcranial windows for ultrasound insonation, and some patients with positive clinical assessments may present residual blood flow even after cerebral arteriography ${ }^{1,7,8}$.

\section{Assessment description}

The recommended parameters for the patient are: patient in dorsal decubitus position; systolic blood pressure above $90 \mathrm{mmHg}$; heart rate above $60 \mathrm{bpm}$; and no hypoxemia $\left(\mathrm{SpO}_{2}>95 \%\right)$.

The parameters for the equipment are: a $2 \mathrm{MHz}$ probe; sample volume between 10 and $15 \mathrm{~mm}$; maximal gain; and low power. 


\section{Step-by-step description of the TCD \\ assessment \\ Insonation of the transtemporal window}

First, identify the middle cerebral artery (MCA) velocity flow by:

a. setting-up insonation depth between 44 and $62 \mathrm{~mm}$;

b. identifying the vessel with flow towards the transducer;

c. evaluating the wave spectrum for each $2 \mathrm{~mm}$ of depth.

\section{Insonation of the suboccipital window}

First, lateral flexion of the neck towards the opposite shoulder.

Secondly, identify the vertebral artery (VA) velocity flow by:

a. using a depth between 60 and $80 \mathrm{~mm}$;

b. ensuring that the flow is projected away from the transducer;

c. evaluating the wave spectrum for each $2 \mathrm{~mm}$.

Thirdly, identify the basilar artery (BA) velocity flow by:

a. using a depth between 80 and $100 \mathrm{~mm}$;

b. ensuring that the flow is projected away from the transducer;

c. evaluating the wave spectrum for each $2 \mathrm{~mm}$.

\section{Insonation of the transorbital window (if a transtemporal window is inappropriate)}

First, reduce the ultrasound power to $10 \%$

Second, identify the carotid siphon velocity flow by:

a. using a depth of between 60 and $80 \mathrm{~mm}$;

b. ensuring that the flow is projected away from or towards the transducer;

c. evaluating the wave spectrum for each $2 \mathrm{~mm}$.

\section{Special situations}

In children younger than two years-old, for whom cranial fontanels are usually opened and the skull is more elastic, intracranial pressure may not increase as it does in adult patients. Therefore, false-negative results may be from persistent encephalic blood flow in patients with a clinical assessment that is compatible with $\mathrm{BD}^{9,10}$. The same results may occur in patients with intraventricular drains or extensive craniotomies. In those cases, exam results should be interpreted with caution ${ }^{4,7,8}$.

\section{Transcranial color duplex}

Modern ultrasound scanners are able to produce real-time brain images, in addition to the pulsatile Doppler signal of blood flow. Duplex scanners combine B-mode imaging with pulsatile wave Doppler measurements. The B-mode image is used to guide the Doppler beam and to place a Doppler sample volume in a region of interest (ROI). Blood vessel images allow the Doppler angle to be measured - by assuming that the blood flow is parallel to the vessel wall. Therefore, the Doppler shift frequency can be calibrated in terms of the blood flow velocity.
Color flow imaging (CFI) systems are similar to the pulseecho B-mode ones, with the exception that both the amplitude and the Doppler shift are measured on the returning echoes. In the absence of the Doppler shift, grayscale information is recorded to the display device, but when a Doppler shift is detected, the display uses color-coding to indicate the measured relative velocity between the transducer and the detected target. Most often, the flow towards the transducer will be coded in one color (often red), and the flow away from the transducer in another one (usually blue). Therefore, two-dimensional color mode recordings from TCCD scanners reveal an interesting pattern: systolic and diastolic flows coexist simultaneously, resulting in a pulsating flashing signal (alternating between red and blue). This unique pattern is termed the 'beacon' signal, and it was observed in all patients at the time of cerebral circulation cessation according to synchronous Doppler signals in all of the studied intracranial vessels ${ }^{11}$. The M-mode system may also be used to identify the reverberating flow pattern that appears before ECA ${ }^{11-14}$.

Results from the two studies revealed a high concordance between TCCD and digital angiography in ECA diagnosis (Level A, Class 2) ${ }^{11,12}$. The main limitations of the TCCD are similar to those of the TCD. Therefore, in patients with external ventricular drainage and extensive craniotomy, an alternative method is recommended. In cases of a poor transtemporal window, it is important to include the transorbital window to access the internal carotid artery flow pattern. A follow-up test is imperative when there is persistent diastolic flow on the carotid siphon.

\section{Assessment description}

The recommended parameters for the patient are: patient in dorsal decubitus position; systolic blood pressure above $90 \mathrm{mmHg}$; heart rate above $60 \mathrm{bpm}$; and no hypoxemia $\left(\mathrm{SpO}_{2}>95 \%\right)$.

The parameters for the equipment are: 1.5 to $5 \mathrm{MHz}$ phased-array transducer; with color and velocity scales adjusted for low amplitude; sample volume between 6 and $10 \mathrm{~mm}$ (pulsatile Doppler); maximal gain and small sample size (color and pulsatile Doppler); not making angle adjustments for the pulsatile Doppler; to avoid triplex mode. Ideally, after identification of the anatomic landmarks and arterial signal on color Doppler, the color image should be frozen and used only as a map to guide sample volume in the ROI.

\section{Step-by-step description of the TCCD assessment}

\section{Insonation of the transtemporal window}

Select B-mode and aim the transducer at a transversal orientation on the transtemporal window.

Identify the anatomic landmarks:

a. midbrain/cerebral peduncles (hypoechogenic signal resembling a butterfly);

b. the minor wing of sphenoid (hyperechogenic); 
c. contralateral temporal bone (hyperechogenic).

Decrease the insonation depth to approximately $70 \mathrm{~mm}$ or to the contralateral boundaries of the cerebral peduncles.

Activate power or color Doppler for the identification of the flow and position of the intracranial arteries by:

a. keeping the color box small;

b. maintaining maximal gain;

c. decreasing the color Doppler scale to low velocity flow.

Identify the intracranial arteries:

a. MCA (minor wing of sphenoid);

b. anterior cerebral artery (middle to the minor wing of sphenoid);

c. posterior cerebral artery (around the midbrain/cerebral peduncles).

Activate the color Doppler to identify the artery spectral patterns.

Freeze the color Doppler and place the sample volume on the ROI. Update the color map after five to ten seconds to confirm the Doppler sample position.

If the color Doppler does not give a signal, place the volume sample of the pulsatile Doppler according to the anatomical landmarks previously detailed by:

a. increasing the sample volume from 10 to $16 \mathrm{~mm}$;

b. placing the sample volume of the pulsatile Doppler around the midbrain and sphenoid bone.

Save the findings and register the obtained information.

\section{Insonation of the suboccipital window}

Lateral flexion of the neck towards the shoulder.

Select B-mode and aim the transducer at a transversal orientation on the median suboccipital window.

Identify anatomic landmarks:

a. clivus (hyperechogenic);

b. foramen magnum (hypoechogenic).

Maintain an insonation depth of approximately $100 \mathrm{~mm}$.

Activate the power or color Doppler to identify the intracranial artery flow and position by:

a. keeping the color box small;

b. maintaining maximal gain;

c. decreasing the color Doppler scale to low velocity flow.

Identify the VA flow (lateral borders of the foramen magnum):

a. depth between 60 and $80 \mathrm{~mm}$;

b. flow is projected away from the transducer;

c. evaluate the wave spectrum for each $2 \mathrm{~mm}$.

Identify the BA flow (VA confluence, "Y" shaped):

a. depth between 80 and $100 \mathrm{~mm}$; b. flow is projected away from the transducer;

c. evaluate the wave spectrum for each $2 \mathrm{~mm}$.

Activate the color Doppler to identify any artery spectral patterns.

Freeze the color Doppler and place the sample volume on the ROI. Update the color map after five to ten seconds to confirm the position of the Doppler sample.

If the colored-Doppler does not give a signal, place the volume sample of the pulsatile Doppler according to the anatomical landmarks previously detailed.

Increase the sample volume from 10 to $16 \mathrm{~mm}$.

Place the sample volume of the pulsatile Doppler around the border of the foramen magnum.

Save the findings and register the obtained information.

\section{Insonation of the transorbital window (if a transtemporal window is inappropriate)}

Reduce the power of all modes to $10 \%$.

Maintain an insonation depth of approximately $80 \mathrm{~mm}$.

Select the B-mode and aim the transducer at a transversal orientation through the patients' closed eyes.

Identify anatomic landmarks: ocular globe (hypoechogenic).

Activate the power or color Doppler to identify the intracranial artery flow and position by:

a. keeping the color box small;

b. maintaining maximal gain;

c. decrease the color Doppler scale to low velocity flow.

Identify carotid siphon flow:

a. depth between 50 and $80 \mathrm{~mm}$;

b. flow is projected either away from or toward the transducer as required;

c. evaluate the wave spectrum for each $2 \mathrm{~mm}$ of depth.

Activate the color Doppler to identify the artery spectral patterns.

Freeze the color Doppler and place the sample volume on the ROI. Update the color map after five to ten seconds to confirm the position of the Doppler sample.

If the color Doppler does not give a signal, place the volume sample of the pulsatile Doppler, according to the anatomical landmarks:

a. increase the sample volume from 10 to $16 \mathrm{~m}$;

b. place the sample volume of the pulsatile Doppler behind the ocular globe.

Save the findings and register the obtained information.

\section{NEUROSONOLOGYTRAINING}

Neurosonology evaluations require extensive training to conduct. To adequately assess and interpret the results, the 
examiner should be very familiar with cranial circulation anatomy and physiology, as well as with the basic concepts of ultrasound physics, such as the Doppler effect and the mechanical wave behavior. Neurosonological assessment also requires knowledge about fundamental neurovascular/neurological concepts, including intracranial stenosis, stroke, cerebrovascular reactivity, microembolic signals, vasospasm, and BD.

The TCD is an operator-dependent method. Therefore, examiners need to be fully trained, certified, and updated to perform neurosonological routine assessments in their clinical practices and to confirm $\mathrm{BD}$. Neurosonologists must be able to perform both TCD and TCCD and they must know how to recognize and avoid the inconsistencies of each method. The confirmation of BD has irreversible consequences since no post hoc corrections can be made according to the Brazilian regulations (Brazilian Council of Medicine, resolution 1826/07).

Thus, we recommend that to perform neurosonological assessments to confirm BD, physicians must be certified by the Brazilian Academy of Neurology or must fulfill at least one of the following requirements: complete at least 200 hours of Neurosonology training at a recognized institution, under the direct supervision of an experienced neurosonologist and provide proof of at least 12 months of experience performing TCD/TCCD exams on a regular basis.

Both the following criteria should also be fulfilled: provide evidence of at least ten exams that confirm $\mathrm{BD}$, under the supervision of an experienced neurosonologist and provide evidence of at least 50 neurosonologic assessments for other neurological conditions, under the supervision of an experienced neurosonologist.

Experienced neurosonologists must be at least five years in practice and be certified by the Neurosonology Department of the Brazilian Academy of Neurology.

\section{NEUROSONOLOGY CRITERIA FOR THE DIAGNOSIS OF CEREBRAL CIRCULATORY ARREST}

Ultrasound has been used to study intracranial diseases since the 1950s, and Leksell has showed this usefulness technique for evaluating complications of traumatic brain inju$\mathrm{ry}^{15}$. In 1978, researchers used echoencephalogram to demonstrate the absence of cerebral circulation in adults, using an indirect sign of lack of midline pulsation. Flow was absent in 26 of 28 patients with $\mathrm{BD}$, and it was present in 18 patients with decreased consciousness ${ }^{16}$. However, the majority of these previous studies exploited the Doppler effect.

The first two reports of using the carotid Doppler for the diagnosis of BD were from Japan and Switzerland, in $1974^{17,18}$. The initial reports of TCD for BD diagnosis were published in $1987^{19,20}$. Over the past 20 years, numerous studies have attempted to validate neurosonography ${ }^{4,5,20-36}$, and the two most important were conducted by Hassler, Steinmetz, Pirschel and Gawlowski ${ }^{5,21}$ and Petty et al. ${ }^{4}$.
In two studies, Hassler et al. evaluated patients with increased intracranial pressure with TCD immediately prior to angiography ${ }^{5,21}$. Several of these patients had deteriorated to $\mathrm{BD}$, and several had not. The authors reported that as the intracranial pressure increased, the end diastolic velocity decreased, and the spectral curve had a sharper peak. When the intracranial pressure was equal to the diastolic one, the diastolic velocity disappeared. Additional intracranial pressure reversed the end diastolic velocity, resulting in a forward flow during the systole and a retrograde flow during the diastole, which is also known as an alternating flow. As the test progressed, only short spikes during early systole were detected. Thereafter, TCD failed to reveal a signal. The alternate flow and the short systolic flow peaks confirmed the cerebral circulatory arrest, which was demonstrated by the arteriography.

Petty et al. ${ }^{4}$ evaluated 54 comatose patients with TCD, 23 of them had confirmed BD (21 were diagnosed using clinical criteria and EEG, and two were diagnosed using clinical criteria only). The TCD criteria for BD that were established by the authors included the insonation of at least two intracranial arteries (bilaterally in the anterior circulation or the BA and an anterior artery) and a flow statement lacking a diastolic component, alternating flow or short peak systolic flows. The absence of signal was not considered compatible with the diagnosis of $\mathrm{BD}$, even when there was a previous TCD examination demonstrating an adequate window. Using these criteria, the specificity and sensitivity of TCD for confirming BD were 100 and 91.3\%, respectively ${ }^{4}$.

\section{INTERNATIONAL GUIDELINES FOR THE DIAGNOSIS OF CEREBRAL CIRCULATORY ARREST}

The American Academy of Neurology published BD diagnostic parameters in 1995, which stated that TCD can be used as a confirmatory test for BD with two caveats; the absence of flow is not consistent with the diagnosis of $\mathrm{BD}$, and standard flow can be either short systolic peaks without flow during diastole or alternating flow ${ }^{37}$.

In 1998, the Neurosonology Research Group of the World Federation of Neurology (WFN) published a consensus opinion on ECA diagnosis? ${ }^{7}$. At that time, only the study carried out by Petty et al. met several of the minimum qualifications for the validation of a diagnostic method ${ }^{4}$; therefore, the authors considered a case series to define BD diagnostic criteria.

According to the WFN, ECA diagnosis could only be confirmed after clinical diagnosis and by two exams that were at least 30 minutes apart, which fulfilled all of the following criteria: short systolic peak (less than $50 \mathrm{~cm} / \mathrm{s}$ ) or alternating flow in the internal carotid arteries or MCAs or posterior circulation; confirmed findings in the extracranial and intracranial circulations; absence of flow considered only in previously evaluated patients with a satisfactory transcranial window; and absence of ventricular drains or large openings in the skull. 


\section{CRITERIA OF THE BRAZILIAN ACADEMY OF NEUROLOGY FOR THE DIAGNOSIS OF CEREBRAL CIRCULATORY ARREST}

Currently, the Brazilian Academy of Neurology follows the neurosonological BD criteria of the WFN, with a couple of modifications; the evaluation of intracranial arteries is sufficient, and only a single test that lasts at least 30 minutes is required, instead of two with a 30-minute interval.

To be eligible for TCD, the patient must meet the clinical criteria for inclusion in the BD protocol, according to current Brazilian regulations. Additionally, a stable hemodynamic status (with or without drugs) is required, and the patient's systolic blood pressure must be greater than $90 \mathrm{mmHg}$. If the patient's systolic blood pressure is lower than this value, the examiner must wait for the patient's blood pressure to increase following fluid replacement and/or the use of vasoactive amines. Otherwise, a diagnosis of ECA cannot be made. In some patients, the blood flow signal can only be observed when the gain and power are increased on the TCD machine.

The characteristic findings of ECA by TCD are the following: short systolic peaks (spectral curves anterograde, with less than $50 \mathrm{~cm} / \mathrm{s}$ of anterograde blood flow velocity), with no flow signal during the remainder of the cardiac cycle (Fig 1A), or an alternating flow (spectral pattern with concurrent anterograde peak systolic and retrograde diastolic inversion; Fig 1B). For cases in which a previous TCD performed during the same hospitalization revealed blood flow in the analyzed vessels, a new examination demonstrating the absence of signal in all examined arteries can also be interpreted as indicative of ECA.

Residual blood flow may be found in almost $20 \%$ of all patients, especially in intracranial carotid arteries and in craniotomy patients; however, these findings often disappear within a few hours. Previous digital angiography studies have demonstrated persistent residual flow in the carotid siphon of BD patients ${ }^{38-40}$. However, other authors have observed that patients with an isolated residual flow in the internal carotid artery siphon suffered from BD, which was confirmed
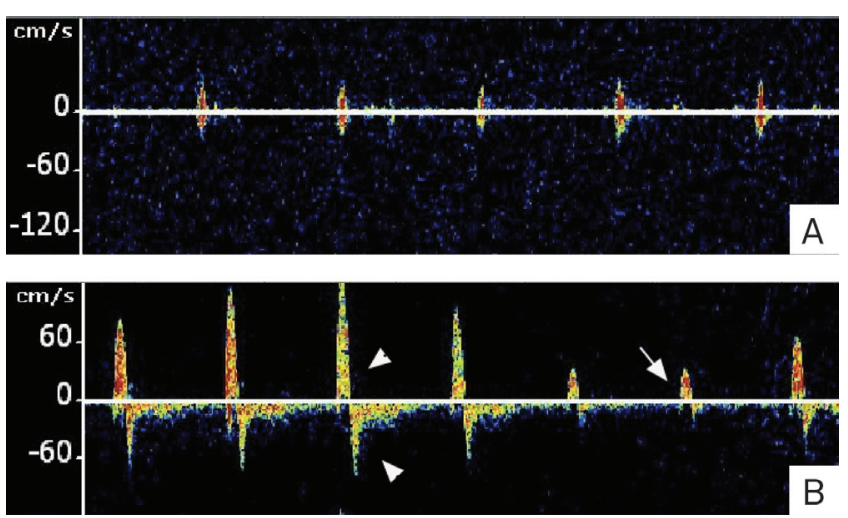

Fig 1. TCD in patients with suspected BD cerebral blood flow velocities characteristics of ECA. (A) middle cerebral artery (58 mm) with a short systolic peak; (B) middle cerebral artery (54 $\mathrm{mm}$ ) with alternating flow, anterograde in systole and reverse in diastole (arrows head), and a short systolic peak (arrow). by other tests (e.g., EEG) ${ }^{41,42}$. Thus, a carotid siphon with anterograde blood flow and all of the remaining arteries exhibiting signs of circulatory arrest can be considered as ECA. However, as shown in Fig 2, the presence of ECA neurosonological signs in both internal carotid arteries siphons is required when there is no satisfactory transtemporal window.

The use of ventricular drains or history of neurosurgical procedures is not related to reduced sensitivity, as demonstrated in a study with 270 patients $^{43}$. In fact, 42\% (86 of 204) of patients who had an initial evaluation that was compatible with $\mathrm{BD}$ also had a history of neurosurgery or craniectomy. Thus, skull openings are not a contraindication to perform the neurosonological examination ${ }^{43}$.

Therefore, ECA diagnosis requires the characteristic findings in the anterior and posterior circulation already described, which are standardized as:

- ultrasonographic patterns: short systolic peaks and/or an alternating flow; when short systolic peaks are present, diastolic flow velocities at or near zero are required; total absence of a blood flow signal should only be considered indicative of ECA in the presence of a previous study in the same hospital admission with an appropriate transcranial window and blood flow identified in the examined arteries.

- in the anterior circulation: observe the findings bilaterally; observe the findings in at least the MCAs; failing the examination of these arteries, ECA must be observed in both carotid siphons.

- $\quad$ in the posterior circulation: must examine VAs and BA; observe the findings in VAs and BA; in the absence of blood flow signal or when BA cannot be studied, ECA must be observed in both Vas; characteristic findings of ECA in the BA concurrent with any residual flow in either of the VAs invalidate the conclusion of the examination as an indication of ECA in this territory.

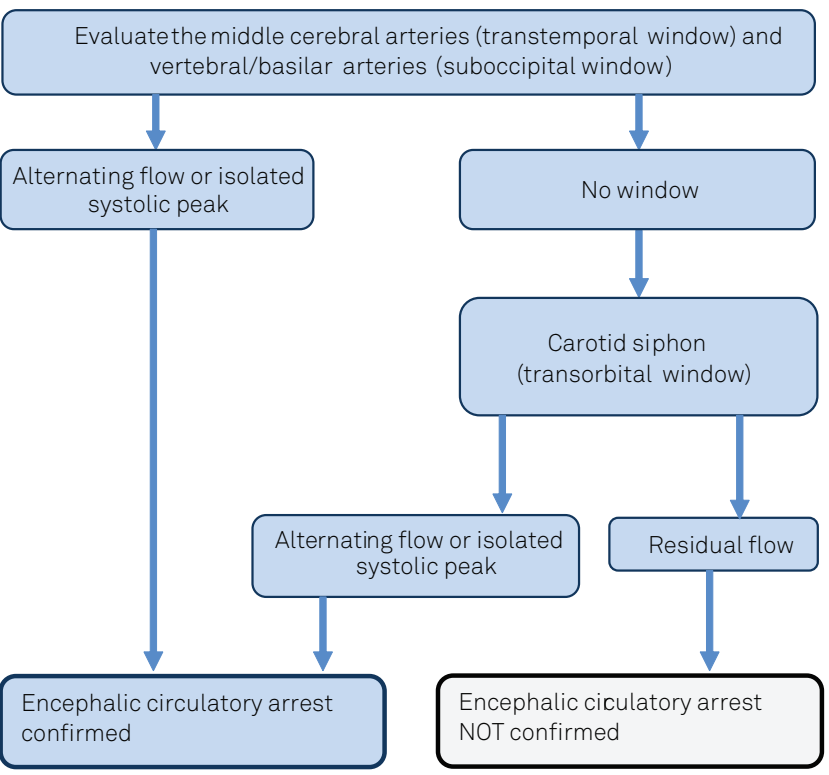

Fig 2. Flowchart for diagnosing encephalic circulatory arrest. 
ECA examination recommendations and diagnostic criteria are summarized in Tables 1 and 2.

The use of complementary methods to evaluate conditions (e.g., blood flow velocity by TCD, electrical activity by EEG) may present conflicting results that make it difficult for family members to accept a BD diagnosis. For instance, TCD may demonstrate ECA in a patient with brain electrical activity assessed by EEG; conversely, EEG may identify isoelectric activity with the TCD revealing residual flow in an intracranial artery. Therefore, the authors recommend using the same screening method for BD diagnosis in sequential evaluations, especially if the first exam yields an uncertain conclusion.

\section{NEUROSONOLOGICAL REPORT TEMPLATE FOR BD DIAGNOSES}

The report should be issued on the letterhead of the institution, hospital or clinic performing the test, and it should contain the following information.

\section{Report header}

The report header should present the institution, hospital, clinic executor or applicant identification; the patient's identification (name, date of birth, age, gender, hospital record); the date and time when the examination was completed; and the blood pressure at the time of examination.

\section{Report body}

The report body should include the description of the examination, specifying the methodology performed and the findings in all of the examined arteries.

Also, it should have the description of the presence or absence of signs compatible with ECA in each analyzed vessel. Justifications should be provided for tests with inconclusive results.

\section{Report conclusion}

The final description must state whether the results are compatible or incompatible with ECA, or whether the test was inconclusive.

The conclusion should also include information about the physician conducting the examination, with his or her full name, signature, and medical license.

\section{Report imaging}

For TCD, attach at least one image (spectral analysis) of each analyzed vessel.

For TCCD, at least one image of each analyzed vessel must be attached to the report, and the images should include the anatomical identification, the B-mode and color Doppler vessel, and the spectrum of pulsed wave Doppler.
Table 1. Recommendations for neurosonological evaluations to confirm encephalic circulatory arrest.

\section{Before the evaluation}

1. Systolic arterial pressure greater than $90 \mathrm{mmHg}$;

2. If necessary, fluid replacement and/or use of vasoactive amines are allowed.

\section{Evaluation}

1. With at least 30 minutes;

2. Evaluate the transtemporal (middle cerebral arteries) and the suboccipital windows (BA and VAs), as well as the transorbital window (carotid siphon) in the selected cases;

3. Search for ECA patterns in the anterior and posterior circulation.

\section{Does not exclude ECA}

1. Neurosurgical procedure or craniectomy;

2. Presence of ventricular drainage;

3. Isolated residual flow in the carotid siphon;

4. No flow or limited ability to evaluate the basilar artery when ECA patterns are demonstrated in both VAs.

BA: basilar artery; VA: vertebral artery; ECA: encephalic circulatory arrest.

Table 2. Diagnosis criteria of encephalic circulatory arrest, according to the Brazilian Academy of Neurology.

\section{Ultrasonographic characteristic patterns to ECA}

1. Short systolic peaks:

2. Alternating flow;

3. Total absence of blood flow signal should be considered indicative of ECA only when a previous study in the same hospital admission, with the appropriate window, revealed a flow signal in the examined arteries.

\section{Definition criteria to ECA}

The characteristic findings described must be identified in the anterior and posterior circulations to establish ECA diagnosis:

\section{In the anterior circulation}

1. Observe the findings bilaterally;

2. Observe the findings at least in the MCAs;

3. Failing the examination of these arteries, the presence of ECA in the carotid siphons is mandatory.

\section{In the posterior circulation}

1. Must examine and observe findings in the VAs and BA

2. In the absence of flow signal or inability to assess BA, ECA must be found in the VAs (bilaterally);

3. Characteristic findings of ECA in the BA that are concurrent with any residual flow in any of the $V A$ s invalidate the conclusion of the examination as an indication of ECA in this territory.

ECA: encephalic circulatory arrest; MCA: middle cerebral artery; VA: vertebral artery; BA: basilar artery.

\section{FINAL REMARKS}

The main objective of this guideline was to standardize neurosonological ECA evaluations (TCD and TCCD) as complementary methods for diagnosing BD. The use of TCCD as a diagnostic tool requires skilled examiners, and future studies should be conducted to demonstrate that TCCD efficacy is similar to that of TCD in BD diagnosis. After comparing these methods, we conclude that TCD should be considered the golden-standard for ECA diagnosis. BD diagnosis will be improved with the use of these guidelines, allowing a faster and more reliable execution and interpretation of neurosonological methods. 
1. Sloan MA, Alexandrov AV, Tegeler $\mathrm{CH}$, et al. Assessment: transcranial Doppler ultrasonography: report of the Therapeutics and Technology Assessment Subcommittee of the American Academy of Neurology. Neurology 2004;62:1468-1481.

2. Goodin DS, Edlund W. Process for developing technology assessments. American Academy of Neurology Therapeutics and Technology Subcommittee; 1999, p. 1-35.

3. Newell DW, Aaslid R (Eds). Transcranial Doppler. New York: Raven Press; 1992, p. 145-151.

4. Petty GW, Mohr JP, Pedley TA, et al. The role of transcranial Doppler in confirming brain death: Sensitivity, specificity, and suggestions for performance and interpretation. Neurology 1990;40:300-303.

5. Hassler W, Steinmetz H, Pirschel J. Transcranial doppler study of intracranial circulatory arrest.J Neurosurg 1989;71:195-201.

6. Zurynski Y, Dorsch N, Pearson I, Smith F, Woods P. The use of transcranial doppler sonography in the diagnosis of brain death. J Neurosurg Anesthesiol 1989;1:323-327.

7. Ducrocq X, HasslerW, Moritake K, et al. Consensus opinion on diagnosis of cerebral circulatory arrest using doppler-sonography: Task force group on cerebral death of the neurosonology research group of the world federation of neurology.J Neurol Sci 1998;159:145-150.

8. Vicenzini E, Pro S, Randi F, et al. Transcranial Doppler for brain death after decompressive craniectomy: Persistence of cerebral blood flow with flat EEG. Intensive Care Med 2010;36:2163-2164.

9. Ahmann PA, Carrigan TA, Carlton D, Wyly B, Schwartz JF. Brain death in children: characteristic common carotid arterial velocity patterns measured with pulsed Doppler ultrasound.J Pediatr 1987;110:723-728.

10. Vicenzini E, Pulitano P, Cicchetti R, et al. Transcranial doppler for brain death in infants: the role of the fontanelles. Eur Neurol 2010;63: 164-169.

11. Poularas J, Karakitsos D, Kouraklis G, et al. Comparison between transcranial color Doppler ultrasonography and angiography in the confirmation of brain death. Transplant Proc 2006;38:1213-1217.

12. Soldatos T, Karakitsos D, Wachtel M, et al. The value of transcranial Doppler sonography with a transorbital approach in the confirmation of cerebral circulatory arrest. Transplant Proc 2010;42:1502-1506.

13. Schöning M, Scheel P, Holzer M, Fretschner R, Will BE. Volume measurement of cerebral blood flow: assessment of cerebral circulatory arrest. Transplantation 2005;80:326-331.

14. Karakitsos D, Poularas J, Karabinis A, Dimitriou V, Cardozo A, Labropoulos N. Considerations for the utilization of transcranial Doppler sonography in the study of progression towards cerebral circulatory arrest. Intensive Care Med 2011;37:368-370.

15. Lekseel L. Echo-encephalography: I. Detection of intracranial complications following head injury. Acta Chir Scand 1955;110:301-315.

16. Uematsu S, Smith TD, Walker AE. Pulsatile cerebral echo in diagnosis of brain death. J Neurosurg 1978;48:866-875.

17. Yoneda S, Nishimoto A, Nukada T, Kuriyama Y, Katsurada K. To-andfro movement and external escape of carotid arterial blood in brain death cases. A Doppler ultrasonic study. Stroke 1974;5:707-713.

18. Despland PA, de Crousaz G. L'apport de l'ultrasonographie Doppler au diagnostic de la mort cérebrale. Schweiz Med Wochenschr 1974:104:1454-1459.

19. Ropper AH, Kehne SM, Wechsler L. Transcranial Doppler in brain death. Neurology 1987;37:1733-1735.

20. Kirkham FJ, Levin SD, Padayachee TS, Kyme MC, Neville BGR, Gosling RG. Transcranial pulsed Doppler ultrasound findings in brain stem death.J Neurol Neurosurg Psychiatry 1987;50:1504-1513.

21. Hassler W, Steinmetz H, Gawlowski J. Trancranial Doppler ultrasonography in raised intracranial pressure and in intracranial circulatory arrest. J Neurosurg 1988;68:745-751.
22. Van Velthoven V, Calliauw L. Diagnosis of brain death: transcranial Doppler sonography as an additional method. Acta Neurochir (Wien) 1988;95:57-60.

23. Newell DW, Grady MS, Sirotta P, Winn HR. Evaluation of brain death using transcranial Doppler. Neurosurgery 1989;24:509-513.

24. Pillay PK, Wilberger J. Transcranial Doppler evaluation of brain death. Neurosurgery 1989;25:481-482.

25. Powers AD, Graeber MC, Smith RR. Transcranial Doppler ultrasonography in the determination of brain death. Neurosurgery 1989;24:8848-89.

26. Shiogai T, Sato E, Tokitsu M, Hara M, Takeuchi K. Transcranial Doppler monitoring in severe brain damage: relationships between intracranial haemodynamics, brain dysfunction and outcome. Neurol Res 1990;12:205-213.

27. Zurynski Y, Dorsch N, Pearson I, Choong R. Transcranial Doppler ultrasound in brain death: experience in 140 patients. Neurol Res 1991;13:248-252.

28. Davalos A, Rodriguez-Rago A, Mate G, et al. Valor del examen Doppler transcraneal en el diagnostico de la muerte cerebral. Med Clin (Barc) 1993;100:249-252.

29. Feri M, Ralli L, Felici M, Vanni D, Capria V. Transcranial Doppler and brain death diagnosis. Crit Care Med 1994;22:1120-1126.

30. Paolin A, Manuali A, Di Paola F, et al. Reliability in diagnosis of brain death. Intensive Care Med 1995;21:657-662.

31. Valentin A, Karnik R, Winkler WB, Hochfellner A, Slany J. Transcranial Doppler for early identification of potential organ transplant donors. Wien Klin Wochenschr 1997;109:836-839.

32. Ducrocq X, Braun M, Debouverie M, Junges C, Hummer M, Vespignani $\mathrm{H}$. Brain death and transcranial Doppler: experience in 130 cases of brain dead patients. J Neurol Sci 1998;160:41-46.

33. Hadani M, Bruk B, Ram Z, Knoller N, Spiegelmann R, Segal E. Application of transcranial Doppler ultrasonography for the diagnosis of brain death. Intensive Care Med 1999;25:822-828.

34. Azevedo E, Teixeira J, Neves JC, Vaz R. Transcranial doppler and brain death. Transplant Proc 2000;32:2579-2581.

35. Lampl Y, Gilad R, Eschel Y, Boaz M, Rapoport A, Sadeh M. Diagnosing brain death using transcranial Doppler with a transorbital approach. Arch Neurol 2002;59:58-60.

36. Dosemeci L, Dora B, Yilmaz M, Cengiz M, Balkan S, Ramazanoglu A. Utility of transcranial doppler ultrasonography for confirmatory diagnosis of brain death: two sides of the coin. Transplantation 2004;77:71-5.

37. The Quality Standards Subcommittee of the American Academy of Neurology. Practice parameters for determining brain death in adults. Neurology 1995;45:1012-4.

38. Greitz T, Gordon E, Kolmodin G, Widen L. Aortocranial and carotid angiography in determination of brain death. Neuroradiology 1973;5:13-9.

39. Bradac GB, Simon RS. Angiography in brain death. Neuroradiology 1974;7:25-8.

40. Kricheff II, Pinto RS, George AE, Braunstein P, Korein J. Angiographic findings in brain death. Ann NY Acad Sci 1978;315:168-83.

41. de Freitas GR, Andre C, Bezerra M, Nunes RG, Vincent M. Persistence of isolated flow in the internal carotid artery in brain death. J Neurol Sci 2003;210:31-4.

42. de Freitas GR, Andre C. Routine insonation of the transorbital window for confirming brain death: a double-edged sword. Arch Neurol 2003;60:1169.

43. de Freitas GR, André C. Sensitivity of transcranial Doppler for confirming brain death: a prospective study of 270 cases. Acta Neurol Scand 2006;113:426-32. 